\title{
Article
}

\section{Reframing 'well-being' in schools: the potential of recognition}

Graham, Anne, Powell, Mary Ann, Thomas, Nigel and Anderson, Donnah

Available at http://clok.uclan.ac.uk/18232/

Graham, Anne, Powell, Mary Ann, Thomas, Nigel ORCID: 0000-0002-53109144 and Anderson, Donnah (2016) Reframing 'well-being' in schools: the potential of recognition. Cambridge Journal of Education . pp. 1-17. ISSN 0305$764 X$

It is advisable to refer to the publisher's version if you intend to cite from the work. http://dx.doi.org/10.1080/0305764X.2016.1192104

For more information about UCLan's research in this area go to http://www.uclan.ac.uk/researchgroups/ and search for <name of research Group>.

For information about Research generally at UCLan please go to http://www.uclan.ac.uk/research/

All outputs in CLoK are protected by Intellectual Property Rights law, including Copyright law. Copyright, IPR and Moral Rights for the works on this site are retained by the individual authors and/or other copyright owners. Terms and conditions for use of this material are defined in the policies page.

\section{CLoK}

Central Lancashire online Knowledge www.clok.uclan.ac.uk

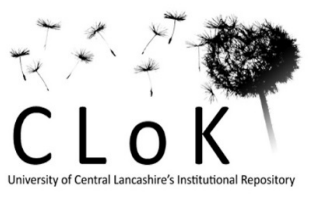




\title{
Reframing 'wellbeing' in schools: the potential of recognition
}

\author{
Anne Graham, Mary Ann Powell, Nigel Thomas and Donnah Anderson \\ Centre for Children and Young People, Southern Cross University, Lismore, Australia
}

\section{Corresponding Author:}

Anne Graham, Centre for Children \& Young People, Southern Cross University, PO Box 157, Lismore NSW, Australia.Ph: 612 66203613.E-mail: anne.graham@scu.edu.au

\section{Other Author Details:}

Mary Ann Powell, Centre for Children \& Young People, Southern Cross University, PO Box 157, Lismore NSW, Australia.Ph: 612 66203605.E-mail: maryann.powell@scu.edu.au

Nigel Thomas, School of Social Work, University of Central Lancashire, Preston, PRI 2HE,Ph:00441772894514Email: npthomas@uclan.ac.uk

Donnah Anderson, School of Psychology, Charles Sturt University, Locked Bag 5000, Port Macquarie, NSW, Australia.Ph: 612 63384580.E-mail: doanderson@csu.edu.au

\section{Acknowledgements}

This work was supported by the Australian Research Council [grant number LP110200656].

\section{Disclosure Statement}

We have no financial interest or benefit arising from the direct application of this research. 


\section{Reframing 'wellbeing' in schools: the potential of recognition}

In Australia and internationally, the wellbeing of children and young people is a core focus of social policy, with a growing imperative to locate wellbeing within the sphere of education. However, the term 'wellbeing' remains ambiguous and the implementation of educational approaches to promote and improve it appear fragmented and ad hoc. In Australia, little is known about how wellbeing is understood and supported in schools, particularly from the perspective of students themselves. This article reports on key findings from an ambitious mixed-methods study funded by the Australian Research Council that investigated conceptualisations and practices around wellbeing in schools. Underpinned by theoretical interests linked to Childhood Studies and recognition theory, the research investigated policy, student and staff perspectives on wellbeing. The findings point to the key role of relationships, providing considerable scope for analysing the salience of Honneth's modes of recognition for wellbeing in schools.

Keywords: student wellbeing; school; relationships; recognition

\section{Introduction}

Children and young people's 'wellbeing' presents as a somewhat ubiquitous, complex and politically imbued field. While the discourse of 'wellbeing' may lend itself justly to capturing our aspirations for children and young people, the term is poorly defined and under-theorised (Amerijckx \& Humblet, 2014; Camfield, Streuli, \& Woodhead, 2010; McAuley \& Rose, 2010). Hence, whilst reference to ‘wellbeing' now pervades a considerable amount of policy nationally and internationally, writers such as Dinham (2006) suggest the term has joined ‘community', 'participation' and 'empowerment' as a kind of 'hurrah' word that escapes meaning:

'well-being' lacks definition, both as a concept and in practice. Thus there emerges

a range of factors identified as inherent in it or against which it is recognizable and/or measurable. Yet, at the same time, there is little or no consensus about what it really means or looks like and therefore to produce and reproduce it, and to know 
that it is there, proves highly difficult except in the most general of terms (p.183).

Despite this, there is an increasing imperative on schools and education systems to address matters of student wellbeing, since this is where young people spend a significant period of their childhoods (ASPA, 2008). As Wyn (2007, p.35) suggests 'learning to "become somebody well”' is arguably a core educational aim and critically important during a period of precipitous social change when knowledge, skills and the information environment are shifting rapidly and the future is largely uncertain. However, little is known in Australia about how wellbeing is understood and facilitated in schools, particularly from the perspective of students themselves and the teachers tasked with supporting their learning. This lack of knowledge, reflective of wider ambiguity around the meaning of wellbeing, represents a significant barrier to the development, implementation and evaluation of approaches that might improve quality of life at school (for both students and teachers) as well as broader educational outcomes.

This article provides an overview of a large-scale Australian study specifically designed to address the gap concerning how wellbeing is conceptualised and practised at school. The study was ambitious in that it included an extensive analysis of policy related to wellbeing in schools, together with focus group interviews with 606 students, interviews with 89 teachers and principals, and an online survey with 9,268 students and 707 staff in primary and secondary schools.

Given the size of the study it is beyond the scope of this paper to report findings in detail (a comprehensive four volume report is available, Graham et al., 2014). Instead, we seek to position the significance of the study in addressing persistent uncertainty around notions of wellbeing in the context of schools. We draw particular attention to the ways in which understandings of wellbeing are enriched by an approach that brings student views into 
dialogue with those of teachers, principals and policy. We also highlight the potential conceptual reframing of wellbeing made possible through the application of recognition theory and key tenets of Childhood Studies.

The paper begins with a brief discussion of the policy context and current evidence around conceptualisations of children's wellbeing, explicating the need for research in this area in the Australian context. We then outline the aims, design and methods of the study, including an overview of relevant aspects of recognition theory and Childhood Studies, before providing a synthesis of the key findings. The discussion considers the implications of these findings in terms of the research objectives, including the explicit emphasis of the study on informing wider educational policy and practice.

\section{Background: Policy and research context}

\section{Conceptualising wellbeing}

As signaled in the introduction, there is significant instability and ambiguity around the term 'wellbeing' both in public policy and popular discourse. Ereaut and Whiting (2008) contend that 'wellbeing' is a cultural construct that signals a shifting set of meanings, that is, it represents what is collectively agreed by a group or number of groups as constituting the Aristotelian notion of 'the good life'. Current policy and research on wellbeing has largely been derived from two broad perspectives: the hedonic approach, which focuses on happiness and defines wellbeing in terms of pleasure attainment and pain avoidance; and the eudaimonic approach, which focuses on meaning and self-realisation and defines wellbeing in terms of the degree to which a person is fully functioning (Ryan \& Deci, 2001). These two views have given rise to different research and knowledge interests that are in some ways divergent, and in others complementary. Nevertheless, both perspectives broadly incorporate notions of flourishing and thriving (Camfield et al., 2010). 
Notwithstanding the conceptual constraints, a sizeable evidence base has emerged in recent years pointing to key determinants of children's wellbeing, which include positive adult-child relationships, a sense of belonging, positive self-esteem and opportunities to be given responsibility and be involved in decision-making (see Bernard, Stephanou, \& Urbach, 2007; Eckersley, 2008). However, much research on wellbeing has continued to focus upon indicators that do not capture these more complex and holistic aspects of wellbeing, or adequately reflect its subjective or relational nature (Ben-Arieh, 2006).

\section{Wellbeing in schools}

In Australia, as in many other international contexts, concerns about children and young people's wellbeing are increasingly evident in major policy statements, for instance the Melbourne Declaration on Educational Goals for Young Australians (MCEETYA, 2008) and the National Safe Schools Framework (MCEECDYA, 2011). Wellbeing is thus increasingly being positioned as 'core business' of schools, yet there is currently no recognised overarching policy framework for the wellbeing of Australian children that schools might articulate with. Nevertheless, a wide range of programs and interventions are now implemented in schools to promote student wellbeing, including those documented in systematic and other reviews in Australia, the UK, United States and elsewhere (see Durlak, Weissberg, Dymnicki, Taylor, \& Schellinger, 2011; McLaughlin, 2008). Initiatives range from targeted to universal interventions, with whole school approaches placing a 'wider emphasis on relationships, pedagogy and community building' (McLaughlin, 2008, p. 353). Unlike the United Kingdom, where national policy on child wellbeing has been developed and is explicitly reflected in legislation (Rose \& Rowlands, 2010), the absence of a cohesive approach in Australia creates little structure around the coordination of such initiatives. Further, the important aspects of wellbeing facilitated at a cultural and relational level - such 
as identity, connection and belonging - can easily become sidelined by concerns about course content, teaching methods, accountability and compliance. Indeed, teachers report a level of dissonance around increasing requirements and expectations to support student wellbeing (Graham, Phelps, Maddison \& Fitzgerald, 2011; Berryhill, Linney, \& Fromewick, 2009).

To date, in Australia, we know little about students' own perspectives and understandings of what wellbeing at school means. Internationally, particularly in the UK and Scandinavia, the importance of student voice in research on wellbeing is better recognised. Studies have started to explore student views about social and emotional wellbeing, and on programs in schools intended to support wellbeing (see Coombes, Appleton, Allen, \& Yerrell, 2013; Hall, 2010; Kuurme \& Carlsson, 2010; Sixsmith et al., 2007). While some research in Australia has sought to understand children and young people's views about wellbeing (Bourke \& Geldens, 2007; Fattore et al., 2007; Gillet-Swan, 2014), very little of this, until very recently, has been in the context of schools (Redmond, Skattebol \& Saunders, 2013). The research outlined below is the first large scale study in Australia to not only seek students' perspectives but to also bring these into dialogue with staff and policy perspectives, with the application of a fresh theoretical lens, provided through recognition theory and Childhood Studies as detailed below.

\section{Overview of the 'Wellbeing in Schools' study}

The aim of this research was to generate new knowledge about wellbeing in schools, with a view to promoting improved outcomes for children and young people. The Australian Research Council funded the project, which included three partner organisations.

The research objectives specifically focused on:

(1) Developing a detailed understanding of how 'wellbeing' in schools is currently understood by students, teachers and educational policy makers; 
(2) Investigating the potential of recognition theory for advancing understanding and improvements in relation to student wellbeing;

(3) Generating new knowledge about how educational policy, programs and practices in schools could more positively impact on student wellbeing.

This article focuses on key themes that emerged from the findings in relation to the first two objectives, in order to respond to the third objective.

\section{Research Design}

This research adopted a mixed methods design and brings together two distinctive theoretical interests, Childhood Studies and recognition theory, applying these to the analysis of policy texts, and the qualitative and quantitative data collected from students and teachers.

\section{Theoretical framework}

\section{Childhood Studies}

Different academic disciplines have approached the study of children in various ways, with methodologies shaped by perceptions of childhood as: an experience; a biological fact; a social category; an artistic and literary construct; a category for historical and demographic analysis; a category of personhood; and as a locus for human rights and policy interventions (James \& James, 2008; James \& Prout, 1997). Childhood Studies offers the potential for interdisciplinary research that provokes new ways of looking at children and childhood, and how these can be researched and theorised. It is an emergent paradigm, catalysed from within sociology and social anthropology (James \& James, 2008), born from a critique of narrow versions of 'the child' and by a commitment to interdisciplinary approaches to research and teaching (Woodhead, 2009). Woodhead (2009) suggests there are three key features that 
characterise contemporary Childhood Studies: the social construction of childhood; the status and rights of children; and childhood and adulthood (intergenerational relationships).

As such, Childhood Studies provokes a conceptual shift from seeing children as the passive victims of life experiences to social actors with their own views and strategies for actively coping with challenges that come their way. It emphasises the importance of children's agency within 'child-centred' scholarship, including the way this takes shape in and through their relationships. Further, children's involvement in research about their wellbeing both recognises their right to participate in matters that affect them and contributes to realising children's rights associated with wellbeing, epitomised and articulated in the United Nations Convention on the Rights of the Child (Camfield et al., 2010; Sixsmith et al., 2007).

\section{Recognition theory}

A second element of this research is the use of recognition theory, which offers an alternative framework for conceptualising how wellbeing is understood and practiced in schools. In this study, recognition theory is drawn upon to investigate the transformative potential of recognition for individual wellbeing (in this study, that of students and teachers) and for social institutions (in this case, schools).

Grounded in critical theory, the work of recognition scholars is largely interested in self-actualisation, social inequality and social justice. This research draws particularly on the work of Honneth (1995, 2001, 2004) who focused especially on the role and importance of human interaction in the formation of individual and social identity. Honneth (1995) proposes three patterns of intersubjective recognition - love, which refers to the emotional concern for the wellbeing and needs of an actual person; rights, which refers to respect for the equal moral accountability of the legal person; and solidarity, which is the evaluation of particular traits and abilities against a background of 'norms'. Honneth generally does not refer to 
children except in the context of primary relationships of love and care, although he has begun to address this more recently, to a limited extent (see, Honneth 2012).

Our starting point, consistent with the Childhood Studies paradigm, is that children also belong to the class of morally responsible persons, are therefore rights-bearers so entitled to respect, and that children are people with talents and capabilities, who contribute to society and culture and are deserving of esteem. Therefore, as Thomas (2012) has previously asserted, we take the view that all three modes of recognition are relevant to children, just as much as to adults. However, for this study, the language of Honneth's three dimensions has been adapted in ways that are consistent with his theoretical underpinnings, but also intelligible in school settings: love, rights and solidarity become 'cared for,' 'respected,' and 'valued' respectively.

The use of recognition theory in this study allows for a deeper examination of the conditions necessary for the formation of identity, including love and relationship (selfconfidence), human dignity (self-respect) and individuals' capacities, achievements and potential contribution to social life (self-esteem) (Graham \& Fitzgerald, 2010). Such characteristics align closely with key determinants of wellbeing for children and young people identified above and with the core tenets of resilience (Bernard et al., 2007; Bernard, 2005).

Together, recognition theory and Childhood Studies offer important insights into how the wellbeing of students in schools is understood and practiced. Since listening to children and responding to their calls for change is central to the interests of Childhood Studies, recognition theory offers a synergistic theoretical 'partner' in that it suggests that such listening and responding begin with, or create the conditions for, the idea of recognition. In other words, the research itself constituted an act of recognition. 


\section{Method}

The research was conducted across three Catholic school regions in Australia, one each from regional New South Wales, metropolitan Victoria and regional Queensland. These regions were intentionally selected on the basis of their willingness to commit for the duration of the project, their strong existing engagement with 'pastoral' work, which offered fertile ground for the aims of the project, and their contrasting approaches to the implementation of wellbeing policy and programs. An advisory group for the research included students as well as project partners and other key stakeholders.

The research was undertaken across 2012-2014 and conducted in four sequential phases, with each phase informed by findings from the previous stages:

Phase 1 - Policy Analysis: Analysis of key relevant local, state and Commonwealth policy regarding wellbeing $(N=80)$;

Phase 2 - Qualitative: Semi-structured interviews with principals and teachers $(N=$ 89); focus groups with primary and secondary students $(N=606)$;

Phase 3 - Quantitative: On-line survey with primary students $(N=3,906)$, secondary students $(N=5,362)$ and staff $(N=707)$;

Phase 4: Analysis and presentation of findings and professional development for schools.

\section{Phase 1: Policy analysis}

Relevant national, state and local (system-level) policy-related documents were analysed from sectors relevant to child wellbeing in schools, including education, health, mental health and child protection. Eighty policies and policy-related documents were selected for close analysis using a combination of content analysis (guided by keywords) supplemented by 
critical discourse analysis (CDA) principles, where policy is approached as discourse (Fairclough, 1995).

Across the range of documentation there were different ideas and approaches, either explicitly articulated or implied, regarding how wellbeing might best be addressed, promoted or enhanced. An emergent analytical framework was developed, which synthesised these implementation approaches within four domains: relationships; systems and structures; environment; and teaching and learning. Each policy document in the review was then analysed for the presence and nature of any content relevant to these domains, with recognition of the fact that there are areas of overlap between the domains.

This first phase of the research, along with an extensive literature review, set the context for and informed the interview schedules and survey instruments for Phases 2 and 3. In particular, understanding how wellbeing is framed in current policy-related documentation, and the implications of this, helped to identify areas of strength, ambiguity and absence requiring investigation in the subsequent phases.

\section{Phase 2: Qualitative}

Phase 2 of the research involved focus groups with students and semi-structured, individual interviews with teachers and principals from the three participating regions. Eighteen schools were selected in consultation with the research partners. From these schools, students were recruited for the study from Years 1 and 2 (aged 6 - 7), Years 5 and 6 (aged $11-12$ ), Year 8 (aged 14) and Year 11 (aged 17). There were 67 focus groups, in which 606 students participated. The process for the focus groups was refined in consultation with students during a pilot process. The major element was rich conversation guided by open questions within a semi-structured process, which took approximately 30 minutes for Years 1-2, and 60 minutes for Years 5-6, 8 and 11. Drawing and brainstorming were primarily engaged during a 
closing activity in which students were asked to portray an ideal 'imaginary school' that would support wellbeing.

Face-to-face interviews were conducted with 89 staff, comprising 18 principals and 71 teachers, taking on average 45 minutes. The interviews were consistent with critical constructivist approaches and relied on dialogic methods that combine observation and interviewing to foster conversation and reflection. This assisted with necessary questioning of deeper assumptions, values, attitudes and beliefs about wellbeing in schools.

While the interview and focus group questions were semi-structured, these were carefully sequenced to move from conceptualisations of wellbeing through to the relevance of recognition concepts. This structure assisted with the coding of a very large volume of transcribed data within QSR International's NVivo 10 Software. The structure also helped to make sense of individual contributions and group discussion threads, because later ideas around relationships and recognition could be analysed in conjunction with earlier conceptualisations of wellbeing. The students' drawings and written contributions for the ‘imaginary schools’ activity were analysed manually for repeated images and words, and cross-referenced to related transcribed discussions.

\section{Phase 3: Quantitative data}

Phase 3 consisted of a cross-sectional online survey delivered via the Qualtrics survey platform. The survey content emerged out of themes identified from Phase 2 and provided an opportunity to triangulate the data - not just in the sense of validating the findings across the wider school body, but also in terms of illuminating new angles to facilitate rich, robust and comprehensive understandings. The survey questions were refined through an iterative process involving consultation with the advisory group and a pilot study to work through comprehension and information technology requirements. The survey asked participants about their conceptualisation of wellbeing, the importance of relationships, having a say, and 
recognition (being cared for, respected and valued) for wellbeing, as well as several demographic questions. A variety of question formats were used, including check box items, rankings, and 7-point Likert scales. Three versions of the survey were used, all broadly similar, but adapted for Year 3-6 students (primary school), Years 7-12 students (secondary school) or school staff (teachers, leadership staff and general school staff).1 Forty-nine schools participated in the surveys (34 primary schools and 15 secondary schools). In total, 3906 primary students, 5362 secondary students, and 707 staff completed the survey across the three regional areas. Completion of surveys took approximately 20 minutes for students and 30 minutes for staff. The data were analysed using a range of appropriate descriptive and inferential analyses with the software program IBM-SPSS (Version 20).

\section{Ethical considerations}

Ethical approval for the pilot and for Phases 2 and 3 of the main study was obtained via the school systems involved, and the Southern Cross University Ethics Committee. Participation in the study was voluntary and consent was sought from all parties involved, including the students themselves. The latter was confirmed once the concept of research and the aims of this particular study were explained to them at the beginning of the focus group and the survey, increasing the likelihood their consent was fully 'informed'. The privacy and confidentiality of all participants was built into the research design, and research field staff were mindful of the potentially sensitive social dynamics that can exist within school settings,

1 Year 1 and 2 students (6-7 years of age) were included in the pilot survey, but this was found to be too challenging for students to complete without significant intervention from teachers. The researchers, in consultation with the Wellbeing Advisory Group, decided not to include Year 1 and 2 students in the survey because the level of teacher intervention required would potentially produce socially desirable responses jeopardising the data. 
particularly amongst the student body. Indeed, the approach taken was guided by leading international ethics-related resources simultaneously being developed by the researchers (Graham et al., 2013). The underlying philosophy of this work is to ensure the human dignity of children is honoured, and their rights and wellbeing are respected throughout the research process, from planning to dissemination. Hence, our approach is premised on understandings that ethics is more than procedural compliance.

\section{Synthesis of findings}

A snapshot of the key findings across the policy, qualitative and quantitative phases are outlined below. This discussion begins by summarising how wellbeing is understood by the student and teacher participants, and conceptualised in the policies reviewed. The focus then turns to the utility of the three modes of recognition (Honneth, 1995) adopted for the research - cared for, respected and valued - as an alternative analytic framing for understanding and supporting wellbeing in schools. We then discuss implications for policy and practice.

\section{Conceptualisations of wellbeing}

Phase 2 explored students' and teachers' understandings of the term 'wellbeing'. A key similarity between the two data sets was the conceptualisation of wellbeing as multidimensional, made up of physical, social, emotional, psychological and spiritual interests. This is consistent with other studies (see for example, Bourke \& Geldons, 2007; Eckersley, 2005; Gillet-Swan, 2014; Soutter, 2011). However, both students and teachers, in this study and others, tended to foreground the social-emotional aspects of wellbeing, reflecting the immediacy of this dimension (see for example, Eckersley, 2005; Hamilton \& Redmond, 2010). Further, although the analysis of teachers' conceptualisations of wellbeing clustered within and across three inter-related spheres - personal, relational and environmental - the relational context was by far the dominant sphere. This sphere 
incorporated extensive data related to teacher-student relationships, parent partnership, school leadership, school counsellors, pastoral care and elements of pedagogy.

The multidimensional nature of students' understandings was reflected in three key themes that framed their conceptualisations: wellbeing as 'being', 'having' and 'doing'. These are summarised in Table 1 below.

Table 1: Students' conceptualisations of wellbeing as being, having and doing2 [insert Table 1 here]

The three key words, 'being', 'having' and 'doing', either implicitly or explicitly prefaced most of the students' descriptions of wellbeing. In framing their responses this way, we acknowledge as centrally important the way in which students conflated definitions of wellbeing (what they perceive wellbeing is) with what they perceive may contribute to wellbeing. This seamless movement between definitions and contributing factors may, as Gillet-Swan (2014) also points out, contribute to the omnipresent nature of wellbeing and the challenges in defining it. Woven throughout these themes of being, having and doing, both relationships and a sense of agency featured centrally.

Students also discussed how not being, having or doing certain things had a negative impact on wellbeing. For example, not looking after yourself or making bad decisions could lead to negative feelings or a felt absence of wellbeing. The absence of wellbeing was described as being sad, unhappy, cranky, bored, anxious and depressed.

Building upon these Phase 2 findings, participants in Phase 3 were given the opportunity to rank their two most important conceptualisations of wellbeing. Confirming the Phase 2 findings, the term 'wellbeing' evoked a range of different responses from students,

2 The inclusions in Table 1 reflect the dominant themes identified by the researchers, rather than listing all the responses of the students. 
including being happy, being safe, being loved, being respected, being healthy and helping others. Confirming the interview data, staff conceptualisations of wellbeing in the survey primarily focused on being connected to people and place, but also emphasised being mentally or psychologically healthy, being happy and being safe.

In the Phase 1 policy analysis the most common two policy constructions were problem-focused, associating wellbeing with safety (most evident in education policy), and mental health (most evident in health sector policy). While such constructions of wellbeing were evident in the student and teacher data they did not feature prominently.

\section{Significance of relationships}

Throughout Phase 2, relationships were a constant reference point for both students and teachers, and were explicitly and implicitly identified as integral to wellbeing. In Phase 3 the importance of relationships for wellbeing was further endorsed with rating questions providing more nuanced insights. Hence, the Phase 2 and 3 findings firmly situated student wellbeing within a range of relationships and highlighted particular interest in student-teacher

relationships. Other relationships that were important were with parents, friends, peers and the principal.

The Phase 2 and 3 data also revealed some important differences between the views of students and teachers. For example, in Phase 2, while students and teachers both reported wanting students to have trusting, respectful, warm relationships with teachers, students placed a stronger and more explicit emphasis on reciprocity and wanting to be treated equally. In Phase 3, students and teachers also placed differing emphases on particular relationships. For example, while noting the diversity of significant people in students' lives, students ultimately rated parents as the most significant relationships for their wellbeing. By contrast, teachers perceived student-teacher relationships as having foremost importance. 
This might partly be explained by the emphasis in questions on 'wellbeing at school', which teachers may have interpreted more narrowly than students.

The importance of relationships was less evident in policy-related documentation. The primary domain for the implementation of wellbeing was a focus on systems and structures (referred to in 56 documents), which tended to outline protocols and procedures related to issues such as students' safety, care and protection, and mental health. Relationships were the second foremost domain, although referred to in only 36 out of 80 documents. Such a policy position is somewhat at odds with both the emphasis placed on relationships for wellbeing in Phase 2 and 3 findings and a growing evidence base that affirms this (Bernard et al., 2007; Bernard, 2005; Eckersley, 2008).

\section{Recognition and wellbeing}

The significance of relationships for children's wellbeing in schools, revealed in the Phase 2 and 3 findings, points to the potential of recognition theory for progressing understandings and practice around wellbeing. Relationships are central to recognition, with acts of recognition and misrecognition, as well as struggles over recognition, occurring in relational spaces (Honneth, 2005; Graham \& Fitzgerald, 2010; Thomas, 2012). The Phase 2 student and teacher data around conceptualisations of wellbeing aligned very closely to all three modes of recognition (being cared for, respected, valued), prior to these concepts being introduced into the student focus groups and teacher interviews. Once the concept of recognition was introduced in Phase 2 (by identifying the modes that make it up) both teachers and students affirmed its resonance with their conceptualisations of wellbeing as earlier described. In Phase 3, this perceived link between wellbeing and recognition was quantified using a very large sample. Key findings relevant to each of the three modes of recognition are presented below. 


\section{Cared for}

The importance of notions of being cared for was especially evident in the Phase 2 data. For instance, for students, 'being loved' was the second most prominent theme (after happiness) in the being conceptualisations of wellbeing. The cared for dimension was also most frequently referred to by teachers who were more conversant with this dimension than any other. Particular attention was placed by both students and teachers in Phase 2 on the importance of care from teachers being genuine, consistent, over and above the 'job description' and beyond a mere sense of duty or obligation. Both students and teachers also perceived trust as central to being cared for, contributing strongly to students having the confidence to express their needs and desires. Students perceived the key role of teachers in schools is to care for students, through such means as communicating their concern for students, noticing when things are not going well for them, facilitating opportunities for care to be expressed between students, supporting and encouraging students, and having conversations with students. Examples such as these are aligned with teachers' comments in which the caring aspect of the teaching role was highlighted and the need for tacit as well as explicit expression of such care was considered a routine feature of teachers’ roles.

In Phase 3, students and staff rated being cared for as important for student wellbeing. Both primary and secondary students emphasised feeling safe at school and teachers making time to help with homework. Secondary students also emphasised that 'feeling that other students like them' was an important aspect of being cared for that was linked to their wellbeing. Staff rated all aspects of being cared for as very important for student wellbeing, particularly emphasising the importance of teachers knowing students well, and students knowing that their teacher cares for them.

In terms of recognition interests, being cared for was also the most evident mode in the policy-related documentation across all sectors, through reference to: caring, supportive 
relationships for students (mostly within school communities); support networks; establishing a sense of connection and belonging for students within the school context; and developing a caring culture.

\section{Respected}

The importance of respect featured prominently for students in Phase 2, particularly for the older age groups, who articulated self-respect and respect for others as central to student wellbeing. Respect was implicit in primary students' 'imaginary schools' drawings and narratives, and identified more explicitly in secondary students' calls for relationships with teachers and other students to be understanding and respectful. Hence, students understood respect in different ways. Whilst many students felt it was something everyone deserves, and which should be exercised equally and with mutuality ('I will respect another person regardless of whether they respect me'), others spoke of respect in highly conditional terms (such as, 'I will not give respect to a person who does not respect me'). In practice, many students described that teachers tended to expect respect, although felt this was not always offered in return. For teachers, too, respect was most apparent in their understanding of the importance of consistently treating students well, regardless of their individual differences. This included having reasonable expectations, being fair and just, ‘following through' and being consistent.

The role of respect in facilitating wellbeing was subsequently strongly endorsed by both teachers and students in the Phase 3 survey. Primary and secondary students emphasised reciprocity, in that both giving and receiving respect with teachers and other students is important for their wellbeing, along with being treated fairly at school, and all students being respected no matter how old they are. Staff rated all aspects of respect as important for student wellbeing, with particular emphases on fairness, students feeling that their teachers respect them, and that students of all ages are respected. 
In Phase 2, students identified 'having privacy' and 'having a say' as important aspects of respect and as contributing to their wellbeing in everyday school life. Teachers also pointed towards students having a say, expressing themselves and actively participating, as key in engendering a sense of belonging in the school community. However, the Phase 3 survey findings highlighted different emphases by students and staff concerning what they get to have a say about at school. For example, the most important aspect for secondary students was having a say about 'who I sit near', whereas this was the least important aspect from the teachers' perspective.

The concept of respect was implied in some policy-related documents, primarily national and Catholic education documentation, in relation to student behaviour, pastoral care and early childhood. The primary contexts for policy references to respect were: respectful relationships, active participation in school activities and processes, and staff having respect for students.

\section{Valued}

While less evident in the Phase 2 interview data than the other dimensions, students and staff in the Phase 3 surveys strongly endorsed being valued as important for student wellbeing. Teachers in Phase 2 described structures within the school in which students were acknowledged, encouraged and supported in their difference, including in relation to abilities and skills. Opportunities to celebrate difference, including what individual students have to offer, were identified as mainly possible through initiatives such as 'home room' and 'house' systems where teachers perceive that students are better known.

Students in Phase 2 emphasised the importance of accepting themselves and others 'for who they are'. An element of being valued then, which overlaps with notions of being respected, is the importance of dialogue with oneself, expressed by students in terms of 
'looking after yourself', not being too self-critical and making good decisions. Students also identified the role of significant others in facilitating and strengthening student wellbeing through valuing their particular gifts, strengths and competencies.

Importantly, the Phase 3 student survey data showed that outward and public signs of recognition by teachers, such as giving awards and writing reports, were not as strongly linked with feeling valued as were more tacit ways of building and expressing solidarity, such as the teacher spending time with a student, listening to the student, knowing the student well, and helping with school work.

Being valued was the least evident in policy of all three modes of recognition and was primarily expressed in relation to valuing diversity and recognising unique individual attributes.

\section{Struggles over recognition and misrecognition}

Students in Phase 2 identified a range of actions constituting misrecognition by teachers with the most frequently cited 'being yelled at'. Such actions were mostly connected with Honneth's second mode of recognition, respect, with experiences of disrespect generating feelings of shame, humiliation, anger and indignation, and impacting negatively on student wellbeing. While students directly named experiences of misrecognition, teachers did not. Rather, teachers and principals named or alluded to the conditions in which misrecognition or non-recognition of students may take place. This is primarily in the space between the aspirational (what they believed should happen in relation to supporting and enhancing student wellbeing) and the actual (what happens in practice).

Opportunities for recognition and misrecognition lie in conversational spaces talking, listening, hearing, acknowledging, responding - which are fundamental to relationships and for recognition to occur. Both students and teachers indicated in Phase 2 that conditions for conversation are not always available, consistent or evident. 
Phase 3 staff survey findings pointed to differences between staff members in how they perceived experiences of misrecognition, particularly in relation to actions such as teachers humiliating students, teachers speaking harshly to students and students being abusive towards other students. Staff who considered such actions had unimportant consequences for student wellbeing were significantly older, had been working in schools longer, were more satisfied with existing policy and wanted less guidance with wellbeing policy, than staff who responded that negative behaviours had important consequences for student wellbeing.

The findings from the three phases of the research, a snapshot of which is provided above, identified significant connections between wellbeing, relationships and recognition, which are discussed below.

\section{Discussion: Wellbeing, relationships and recognition}

The findings indicate that teachers and students consider schools have an important role to play in student wellbeing, thus lending further weight to the identification of schools, in policy and practice discussions, as key sites for promoting the wellbeing of children and young people (Hamilton \& Redmond, 2010; Wyn, 2007). Central to this is examining how the findings can inform policy, programs and practice in schools in the future. This section returns to the three research objectives to briefly discuss some of the implications for improvement in this critically important area of education.3

3 More detailed discussion of these implications for relationships, systems and structures, teaching and learning, and environment are reported in Volume 4 of the research report (Graham et al., 2014). 
Research objective one: The ways in which wellbeing is currently conceptualised in policy and practice have significant implications for the limits and possibilities of how it might be improved in schools. Wellbeing was perceived as multidimensional and relationship-based by teachers, principals, students and in some policy-related documentation. However, this is at odds with the current Australian policy environment overall, particularly pertaining to schools, which the policy analysis indicates can best be described as fragmented and ad hoc. This is evidenced by the range and nature of documentation that constitutes guidance in relation to student wellbeing, the differences across states and the lack of an over-arching framework.

Findings from the three phases of the study, particularly Phases 2 and 3, emphasise the importance of teacher-student relationships, and other relationships in and outside schools, to support student wellbeing. However, policy gives less attention to the importance of relationships for children's wellbeing than other domains for implementing approaches to wellbeing (namely systems and structures, environment, and teaching and learning). This may be related, in part, to the more simplistic understandings of wellbeing evident in policies and related documentation, which tend to focus on specific aspects, such as safety or mental health, rather than multidimensional approaches. The present study's support for multidimensional conceptualisations of wellbeing and the importance of relationships for wellbeing signals the need to move the wellbeing agenda away from more narrowly focused to broader, holistic and universal approaches. This is consistent with other research in which whole school approaches, where wellbeing is embedded in the culture as well as the curriculum of the school, have been identified as the most likely to be effective in realising the determinants of wellbeing (see Noble et al., 2008; Wells, Barlow, \& Stewart-Brown, 2003). 
Research objective two: The findings from the study indicate the potential of recognition theory for elucidating core priorities in efforts to better support student wellbeing. This theory grounds wellbeing in relationships and can be used to better understand the significance of relationships for students. Recognition of the individual, across the three dimensions identified by Honneth (1995), occurs in the context of reciprocal relationships. Recognition theory acknowledges that inherent intersubjective tensions and struggles over recognition are essential drivers of individual identity development and broader social change. While some dimensions of recognition are implied in certain policy related documents, the explicit use of a recognition lens has not featured in policy to date.

Research objective three: Together, findings from the three phases of the research generate new knowledge about how educational policy, programs and practices in schools could more positively impact student wellbeing. It is critically important to broaden definitions and understandings of wellbeing beyond a singular focus on outcomes such as students' success, school engagement or meeting mental health needs. In doing so, the understandings need to be conceptually grounded in relational, environmental and personal spheres, with the primary emphasis on relationships. This requires clearer defining of the term 'wellbeing' at policy and practice levels. School staff need to be familiar with the myriad ways in which wellbeing is integrated throughout the above spheres in order to identify and engage confidently with priority actions and concerns.

The findings indicate that an emphasis on relationships needs to be embedded throughout education policy and practice, including within structures and systems, and in professional learning at both pre-service and in-service levels, to support student wellbeing. Recognition theory potentially provides a relationship-based framework for schools to foster wellbeing for all members of the school community. 


\section{Limitations}

As far as possible, any perceived limitations of the study were addressed in subsequent phases. For example, schools were asked to identify a diverse range of students from within the relevant age groups to invite to participate in the Phase 2 focus groups. While the researchers emphasised the importance of hearing from a range of students, including those who may not usually be chosen as representatives, this form of selection carries an inherent risk that certain students' voices are left unheard. However, all students then had the opportunity to contribute via the survey in Phase 3. Similarly, whilst this study worked specifically with the Australian Catholic school sector, a follow-on study is currently underway, which extends the research and analysis into the government school sector as well.

Previously it has been flagged that a decision was taken not to continue with the Year 1-2 survey given challenges with survey validity. While not a major limitation given this cohort was still included in the Phase 2 focus groups, there is nevertheless an absence of these younger 'voices' in the larger scale survey.

\section{Conclusion}

This is the first research undertaken in Australia or elsewhere that empirically tests recognition theory and investigates its potential in the context of wellbeing in schools. When combined with key understandings about children and childhood offered through Childhood Studies, the theoretical (as well as applied) contribution of this research is highly significant. Recognition theory offers a potentially powerful tool for generating insights that enable the normative evaluation of how a social setting (in this case a school) can be organised so that everyone (including children and young people) enjoy the recognition which is due to them.

The findings from this study generated important, nuanced knowledge about wellbeing in schools. The policy analysis identified the need for whole school approaches to 
wellbeing, and policy agendas that put relationships at the fore of implementation strategies. The qualitative phase provided rich data and insight into student and staff experiences of wellbeing in schools. The quantitative phase tested and extended the qualitative findings on a very large sample across three regions. These findings offer new and holistic understandings of how wellbeing is conceptualised and how it can be facilitated or impeded in schools. Both the qualitative and quantitative data confirm the significance of relationships for student wellbeing, but also raise areas of tension between student and teacher perspectives about reciprocity in relationships. Together, these findings suggest that programs and policies to enhance wellbeing in schools can be understood through recognition theory, and the centrality of being cared for, respected and valued by teachers, schools and broader societal institutions. 


\section{References}

Amerijckx, G. \& Humblet, P. (2014). Child well-being: What does it mean? Children \& Society, 28, 404-415.

Angner, E. (2009). Subjective measures of well-being: Philosophical perspectives. In H. Kincaid \& D. Ross (Eds.), The Oxford handbook of philosophy of economics. Oxford: Oxford University Press.

ASPA. (2008). Policy position statement: Student wellbeing. Kingston, ACT: Australian Secondary Principals Association.

Ben-Arieh, A. (2006). Measuring and monitoring the well-being of young children around the world. Paper commissioned for the EFA Global Monitoring report 2007 - Strong foundations: Early childhood care and education (1-33).

Bernard, H., Stephanou, A., \& Urbach, D. (2007). ASG student social and emotional health report: A research project conducted by the Australian Council for Educational Research. Melbourne: Australian Scholarships Group.

Bernard, M. (2005). The learning of resilience. Education Horizons, 8(6), 22-23.

Berryhill, J., Linney, J., \& Fromewick, J. (2009). The effects of education and accountability on teachers: Are policies too stress-provoking for their own good? International Journal of Education Policy and Leadership, 4(5), 1-14.

Bourke, L., \& Geldens, P. (2007). Subjective wellbeing and its meaning for young people in a rural Australian center. Social Indicators Research, 82, 165-187.

Camfield, L., Streuli, N., \& Woodhead, M. (2010). Children’s well-being in developing countries: A conceptual and methodological review. European Journal of Development Research, 22, 398-416.

Coombes, L., Appleton, J. V., Allen, D., \& Yerrell, P. (2013). Emotional health and well-being in schools: Involving young people. Children \& Society, 27(3), 220232. doi: 10.1111/j.1099-0860.2011.00401.x

Dinham, A. (2006). Raising expectations or dashing hopes?: Well-being and participation in disadvantaged areas. Community Development Journal, 42(2),181-193.

Durlak, J. A., Weissberg, R. P., Dymnicki, A. B., Taylor, R. D., \& Schellinger, K. B. (2011). The impact of enhancing students' social and emotional learning: A meta-analysis of school-based universal interventions. Child development, 82(1), 405-432. 
Eckersley, R. (2005). What is wellbeing, and what promotes it? Background to a manifesto for wellbeing. In The Australia Institute (Ed.), The Wellbeing Manifesto. Canberra: The Australia Institute. Retrieved from http://www.wellbeingmanifesto.net/wellbeing.html

Eckersley, R. (2008). Never better - or getting worse? The health and wellbeing of young Australians. Weston: Australia 21.

Ereaut, G., \& Whiting, R. (2008). What do we mean by 'wellbeing'? And why might it matter? Research Report DCSF-RW073. London: Department for Children, Schools and Families (DCSF).

Fairclough, N. (1995). Critical discourse analysis: The critical study of language. London: Longman.

Fattore, T., Mason, J., \& Watson, E. (2007). Children's conceptualisation(s) of their well-being. Social Indicators Research, 80, 5-29.

Gillett-Swan, J. (2014). Investigating tween children's capacity to conceptualise the complex issue of wellbeing. Global Studies of Childhood, 4, 64-76.

Graham, A., \& Fitzgerald, R. (2010). Children's participation in research: Some possibilities and constraints in the current Australian research environment. Journal of Sociology, 43(2), 133-147.

Graham A, Fitzgerald R, Powell M, Thomas N, Anderson DL, White NE \& Simmons, CA (2014) Improving approaches to wellbeing in schools: What role does recognition play? Final Report: Volumes 1-4. Centre for Children and Young People, Southern Cross University, Lismore.

Graham, A., Phelps, R., Maddison, C., \& Fitzgerald, R. (2011). Supporting children’s mental health in schools: Teacher views. Teachers and Teaching: Theory and Practice, 17(4), 479-496.

Graham, A., Powell, M. A., Taylor, N., Anderson, D., \& Fitzgerald, R. (2013). Ethical Research Involving Children. Florence: UNICEF Office of Research - Innocenti. Retrieved from www.childethics.com

Hall, S. (2010). Supporting mental health and wellbeing at a whole-school level: Listening to and acting upon children's views. Emotional and Behavioural Difficulties, 15(4), 323-339. doi: 10.1080/13632752.2010.523234 
Hamilton, M., \& Redmond, G. (2010). Conceptualisation of social and emotional wellbeing for children and young people, and policy implications. Sydney: Social Policy Research Centre.

Honneth, A. (1995). The struggle for recognition: The moral grammar of social conflicts. Cambridge: Polity Press.

Honneth, A. (2001). Recognition or redistribution? Changing perspectives on the moral order of society. Theory, Culture \& Society, 18(2-3), 43-55.

Honneth, A. (2004). Recognition and justice: Outline of a plural theory of justice. Acta Sociologica, 47(4), 351-364.

Honneth, A. (2012) The I in we: Studies in the theory of recognition. Cambridge: Polity Press.

James, A., \& James, A. (2008). Key concepts in Childhood Studies. London: Sage.

James, A., \& Prout, A. (Eds.). (1997). Constructing and reconstructing childhood: Contemporary issues in the sociological study of childhood (2nd ed.). London: Falmer Press.

Kuurme, T., \& Carlsson, A. (2010). The factors of well-being in schools as a living environment according to students' evaluation. Journal of Teacher Education for Sustainability, 12(2), 70-88. doi: 10.2478/v10099-009-0055-9

McAuley, C., \& Rose, W. (2010). Child well-being: Current issues and future directions. In C. McAuley \& W. Rose (Eds.), Child well-being: Understanding children's lives. London: Jessica Kingsley Publishers.

MCEECDYA. (2011). National safe schools framework. Canberra: Education Services Australia - Ministerial Council on Education, Early Childhood Development and Youth Affairs (MCEECDYA), Australian Government Department of Education, Employment and Workplace Relations.

MCEETYA. (2008). Melbourne declaration on educational goals for young Australians. Melbourne: Ministerial Council on Education Employment Training and Youth Affairs.

McLaughlin, C. (2008). Emotional well-being and its relationship to schools and classrooms: A critical reflection. British Journal of Guidance \& Counselling, 36(4), 353-366. doi: 10.1080/03069880802364486

Noble, T., McGrath, H., Wyatt, T., Carbines, R., \& Robb, L. (2008). Scoping study into approaches to student wellbeing: Final Report. Australian Catholic University: Report to the Department of Education, Employment and Workplace Relations, 
Erebus International: Report to the Department of Education, Employment and Workplace Relations.

Redmond, G., Skattebol, J., \& Saunders, P. (2013). The Australian child wellbeing project: Overview [Draft]. Australian Child Wellbeing website: Flinders University, the University of New South Wales, and the Australian Council for Educational Research.

Rose, W., \& Rowlands, J. (2010). Introducing the concept of child well-being into government policy. In C. McAuley \& W. Rose (Eds.), Child well-being: Understanding children's lives. London: Jessica Kingsley Publishers.

Ryan, R. M., \& Deci, E. L. (2001). On happiness and human potentials: A review of research on Hedonic and Eudaimonic well-being. Annual Review of Psychology, 52(1), 141-166.

Sixsmith, J., Gabhainn, S., Fleming, C., \& O'Higgins, S. (2007). Children's, parents' and teachers' perceptions of child wellbeing. Health Education, 107(6), 511-523.

Soutter, A. (2011). What can we learn about wellbeing in school? Journal of Student Wellbeing, 5(1), 1-21.

Thomas, N. (2012) Love, rights and solidarity: Studying children's participation using Honneth's theory of recognition. Childhood, 19(4), 453-466.

Wells, J., Barlow, J., \& Stewart-Brown, S. (2003). A systematic review of universal approaches to mental health promotion in schools. Health Education Research, 103(4), 197-121.

Woodhead, M. (2009). Childhood studies: Past, present and future. In M. Kehily (Ed.), An introduction to Childhood Studies (2nd ed., pp. 17-34). London: Open University Press.

Wyn, J. (2007). Learning to 'become somebody well:' Challenges for educational policy. The Australian Educational Researcher, 34(3), 35-52. 